Revista Internacional de Apoyo a la Inclusión, Logopedia, Sociedad y Multiculturalidad.

Volumen 6, Número 1, enero 2020, ISSN: 2387-0907. DOI: https://doi.org/10.17561/riai.v6.n1.07

\title{
Pedagogia de Projetos: práxis pedagógicas como instrumento de avaliação inovadora no processo de ensino aprendizagem.
}

Project Pedagogy: pedagogical praxis as an innovative assessment tool in the teaching-learning process.

Dilce Melo Santos

Faculdade Regional de Filosofia, Ciências e Letras de Candeias -FAC, (Brasil) Colégio Estadual de Aplicação Anísio Teixeira - CEAAT - IAT. Salvador (Brasil) dilcemellotcc@hotmail.com

Nadja Melo Leal

Colégio de Aplicação Anísio Teixeira - CEAAT - IAT - Salvador - Bahia (Brasil) lealnadja@hotmail.com

Fecha recepción: 25/09/2019

Páginas 76-87

Fecha aceptación: 25/12/2019

\section{Resumo.}

A educação precisa acompanhar as transformações da sociedade, assim, é fundamental mudanças de paradigmas nas práxis pedagógicas e no currículo. Por tanto, buscamos investigar como acontece a pedagogia de projetos: práxis pedagógicas como instrumento de avaliação inovadora no processo de ensino aprendizagem. $\mathrm{O}$ objetivo desse artigo é investigar como a pedagogia de projetos pode ser utilizada enquanto metodologia e instrumento de avaliação interativos, tendo como questão problematizadora verificar se a pedagogia de projetos oportuniza a aprendizagem significativa promovendo o conhecer, fazer, ser e conviver. Esse estudo passou pelo rigor da Metodologia da Pesquisa Cientifica e fundamentou-se nas ideias de autores como: Delors (2001), Hernandez e Ventura (1994), Perrenoud (1999), dentre outros. Pode-se descrever então, que após análise sobre a fundamentação teórica e a realidade da escola, considera-se que a Pedagogia de Projetos oportuniza uma Metodologia que propicia a aprendizagem mais significativa, pois o estudante ao interagir com outros na construção de um projeto se envolve em uma experiência educativa em que o processo de construção de conhecimento não só está relacionado às práticas de vida, confunde-se ou é a própria vida dentro e fora do âmbito escolar.

Palavras chave: pedagogia de projetos; metodologia; instrumento de avaliação; aprendizagem significativa; avaliação

\section{Abstract.}

Education needs to accompany the transformations of society, so it is fundamental to change paradigms in pedagogical praxis and curriculum. Therefore, we seek to investigate how project pedagogy happens: pedagogical praxis as an innovative assessment tool in the teaching-learning process. The purpose of this paper is to 
investigate how project pedagogy can be used as an interactive assessment methodology and instrument, with the problematizing question of verifying if project pedagogy provides meaningful learning by promoting knowledge, doing, being and living together. This study went through the rigor of the Methodology of Scientific Research and was based on the ideas of authors such as: Delors (2001), Hernandez and Ventura (1994), Perrenoud (1999), among others. It can be described then that after analysis of the theoretical foundation and the reality of the school, it is considered that Project Pedagogy provides a Methodology that provides the most meaningful learning, because the student interacting with others in the construction of a project. It involves in an educational experience in which the process of knowledge construction is not only related to life practices, is confused or is life itself inside and outside the school.

Keywords: project pedagogy; methodology; evaluation instrument; meaningful learning; evaluation

\section{1.-Introdução.}

Na sociedade moderna, temos contestações no âmbito das práticas educacionais relativo à pedagogia de projetos que tem sido uma estratégia que aponta os métodos tradicionais de ensino e revela uma nova metodologia educativa como instrumento de avaliação inovadora no processo de ensino aprendizagem. Possibilitando, assim, uma construção de conhecimento de forma mais global, capaz de transformar aulas monótonas e antiquadas em verdadeiras fontes de conhecimentos.

Com as mudanças sociais e educacionais cada vez mais exige um ser completo, com competências e habilidades para atuar no mundo e dar conta em atender os aspectos pessoal, profissional e social exigidos pelo mundo contemporâneo. Este ser é formado pelo conhecimento que aprende na escola, colégio, academia e pelas descobertas construídas ao longo da história humana. E nesse processo, todo conhecimento é construído em estreita relação com os contextos em que são utilizados, sendo impossível separar os aspectos cognitivos, emocionais e sociais, pois a formação dos alunos não pode ser pensada apenas como uma atividade intelectual. Nesse sentido, compreende-se a necessidade de uma educação mais interativa, que considere 0 estudante em sua totalidade. Assim, percebe-se que os paradigmas que envolvem a educação precisam ser repensados e reconstruídos de modo que atendam as expectativas da sociedade atual. Para isso, é necessária uma nova abordagem na prática educativa que contemplem a construção do conhecimento em prol de conhecer, fazer, ser e conviver (Delors, 2001, p. 52).

Diante deste paradigma, se faz urgente a inovação pedagógica em prol de metodologias de ensino e de novo instrumentos de avaliação da aprendizagem. Considerando que eles são constituídos respectivamente e são complementares no processo educativo como instrumento básico no processo de transformação pessoal e social. Por tanto, é fundamental que haja um conjunto de mudanças nos espaços de conhecimentos, com o envolvimento da comunicação, da informação e da formação 
integral propriamente dita, que permita o repensar da dinâmica do processo de ensino aprendizagem e por conseguinte uma mudança de padrão.

Para Oliveira (2011), a práxis pedagógica é um processo global importante que permite "aprender participando, vivenciando sentimentos e atitudes", ou seja, desenvolver atividades pedagógicas por meio de projetos é uma atuação que permite múltiplas aprendizagens, pois há uma variedade de estratégias para trabalhar de forma integral estimulando o compreender grupal e socia. É fundamental também, rever o processo de avaliação da aprendizagem, pois, ainda se usa instrumentos obsoletos que não atende as mutações da aprendizagem. A avaliação da aprendizagem deve ser formativa e processual (Oliveira, 2011, p.45).

Segundo Luckesi (1999), nesse aspecto destaca que esta é tarefa cotidianamente necessária e permanente no trabalho docente, pois deve acompanhar o processo de ensino aprendizagem. Através dela, pauta-se os resultados obtidos na trajetória do trabalho do professor e dos estudantes e são todo tempo confrontados com os objetivos descritos no planejamento, como também apontará dificuldades e se necessário redirecionará e redimensionará o trabalho pedagógico, determinando novos caminhos para encaminhamento da efetiva aprendizagem (Luckesi, 2006, p.62). Assim, o presente Artigo discorre sobre a importância do trabalho com a pedagogia de projetos como metodologia que pode inovar a práxis pedagógica e também como instrumento de avaliação da aprendizagem que pode promover a construção do conhecimento integral e significativo.

Ventura (1994), assevera que, a pedagogia de projeto oportuniza aos estudantes, um conhecimento integral, possibilitando uma interdisciplinaridade, esclarecendo que "o conhecimento não é exclusividade de apenas determinada disciplina. Como o próprio autor ressalta, a articulação dos conhecimentos é objetivo fundamental para se romper com a forma rígida de enquadrar os conteúdos" (Ventura, 1994, p.23). E neste aspecto, é pertinente compreender que essa prática de se trabalhar por meio da pedagogia de projetos auxilia na formação integral dos estudantes, já que cria diversas oportunidades de aprendizagem conceitual, atitudinal, procedimental para os mesmos.

Nessa conjuntura, esse estudo teve como questão problematizadora verificar Como a Pedagogia de Projeto pode promover a integração das disciplinas do currículo em uma práxis pedagógica interativa e um instrumento de avaliação formativo que promova 0 conhecer, fazer, ser e conviver em prol aprendizagem significativa. Prontamente esse questionamento tem como hipótese: supor que a Pedagogia de Projetos promove a integração das disciplinas do currículo, além de oportunizar a aprendizagem que perpasse pelos pilares da educação supracitados. Esta metodologia pode definir que os saberes apreendidos no processo de educação formal estejam integrados com os saberes sociais, pois o estudante aprenderá algo que faz sentido e tem significado em sua vida, compreenderá o valor do objeto a ser investigado e assim desenvolverá atitudes e conceitos indispensáveis à resolução de problemas sociais e culturais, se posicionando como sujeito e protagonista de sua ação. 
Para Hernandez e Ventura (1994) a importância de trabalhar com projetos, destacando suas possibilidades e os caminhos, aproxima a escola e o professor realidade e da identidade do estudante como também, desconstrói a função da escola de apenas e somente ensinar conteúdo. E que a pedagogia de projetos leva em consideração 0 que acontece para além dos muros que rodeiam a escola, as transformações sociais e os saberes extraclasses, como também a enorme produção de informação que caracteriza a sociedade contemporânea, estabelecendo um diálogo crítico com todos esses fenômenos e instituições (Hernandez e Ventura,1994, 32).

Deste modo, o objetivo geral foi investigar como a Pedagogia de Projeto pode ser utilizada como metodologia e instrumento de avaliação que efetive o processo de aprendizagem eficaz. Esta pesquisa se justifica por apresentar como a Pedagogia de Projetos oportuniza a articulação ente as disciplinas do currículo escolar, logo, articulam os diversos saberes. Como também, tem enfoque integrador na construção de conhecimentos que transgrida o formato da educação tradicional de transmissão de saberes compartimentados e selecionados pelo professor, não sendo uma metodologia, mas uma forma de refletir sobre a escola e sua função (Hernandez e Ventura, 1994, p.41).

\section{2.-A Inovação Pedagógica na Educação a partir da Pedagogia de Projetos.}

Segundo Garcia (1980) inovar, significa "introduzir mudanças num objeto de forma planejada, visando produzir melhoria no mesmo." enfatizando que inovação do trabalho docente, da práxis pedagógicas requer metodologias de ensino interativas e descreve que para isso é necessário um conjunto de mudanças, em meio a uma realidade nova, denominada de espaço do conhecimento com uma inovação pedagógica, envolvendo comunicação, informação e formação. Neste sentido, a modernização da educação precisa ser repensada, pois a dinâmica do conhecimento deve ter sentido mais amplo e isso requer novas funções do professor como mediador criativo deste processo (Garcia,1980, p.56).

Para uma práxis pedagógica a inovação deve romper o modelo fragmentado de educação e recriar a escola. E nesse sentido, a educação formal precisa acompanhar as mudanças que acontecem no mundo, algumas mudanças pedagógicas têm ocorrido, de forma lenta, e ainda com resistências por parte de alguns professores. 0 estudante do século XXI requer professores pesquisadores, reflexivos, criativos e resilientes. Assim, a concepção de escola e sua função social devem ser repensadas, pois o processo de ensino aprendizado compartimentado, com currículo fragmentado e distanciado das transformações sociais e das vidas dos alunos, não são mais possíveis, com sujeitos aprendentes dentro da escola, sem autonomia e participação na construção de seus saberes, faz com que a aprendizagem perca seu significado. O modelo de educação tradicional necessita de mudança de paradigmas, a práxis docente precisa está voltada para um ensino aprendizagem em que o estudante seja motivado a pesquisar, refletir, conhecer, fazer questionar, ser e conviver. Tais inovações pretendem favorecer mudanças nas concepções e modos de atuar dos professores, na gestão das instituições de ensino e nas próprias funções da escola (Dawbor, 1994, p.28). 
Diante do exposto, compreende-se que o conceito de inovação no que tange a perspectiva pedagógica, comprova que o professor deve buscar formação continuada em prol de procedimento inovador voltado para a concepção de Educação de qualidade que promova ações e procedimentos que se concretizam de forma dinâmica, diversificada, efetiva e significativa. Nessa premissa, deve-se oportunizar sempre a interdisciplinaridade, a contextualização, a problematização e a construção do conhecimento. Entende-se que as instituições de ensino ainda enfrentam um grande desafio, que é tornar-se um espaço de aprendizagem interativo, inter e transdisciplinar, inovador, prazeroso, contextualizado e significativo. Desse modo, 0 professor precisa estar aberto às mudanças e procurar refletir sua práxis pedagógica, enquanto ação educacional transformadora.

Nessa perspectiva, Dawbor (1994), elenca as transformações necessárias e significativas que o professor deve obter para efetivar a inovação no processo educativo, assim é preciso: 0 repensar de forma mais dinâmica 0 universo de conhecimento a trabalhar, em que neste assumem maior importância as metodologias, reduzindo-se ainda mais a dimensão "estoque" de conhecimentos a transmitir; a transformação da cronologia do conhecimento: a visão do homem que primeiro estuda, depois trabalha e depois de aposenta, torna-se cada vez mais anacrônica, e a complexidade das diversas cronologias aumenta; a modificação profunda da função do educando, em particular do adulto, como sujeito da própria transformação diante da diferenciação e riqueza dos espaços de conhecimento nos quais deverá participar; a vinculação da luta pelo acesso aos espaços de conhecimento ao resgate da cidadania, em particular para a maioria pobre da população, como parte integrante das condições de vida e de trabalho; [...], levando a um processo reequilibrado da sociedade quando hoje apenas reforçam as polarizações e desigualdades. (Dawbor, 1994, p.123).

Diante desse contexto, Dawbor (1994), nos afirma que o processo de aprendizagem efetivo é uma das principais preocupações das pesquisas em educação, pois, esta precisa perpassar pelos pilares da educação que envolve 0 aprender a conhecer, a fazer, a ser e a conviver. Para Delors (2001) esclarece que: aprender a conhecer prioriza-se o domínio dos próprios instrumentos do conhecimento, considerado como meio e como fim. Meio, enquanto forma de compreender a complexidade do mundo, condição necessária para viver dignamente, para desenvolver possibilidades pessoais e profissionais, para se comunicar. Fim, porque seu fundamento é o prazer de compreender, de conhecer e de descobrir. $\mathrm{O}$ aprender a fazer proporciona forma mais ampla, envolve competências e habilidades que torna o indivíduo apto para enfrentar numerosas situações, algumas das quais são imprevisíveis, além de facilitar o trabalho em equipe que, atualmente, é uma dimensão negligenciada pelos métodos de ensino. Já o aprender a ser supõe a preparação do indivíduo para elaborar pensamentos autônomos e críticos e para formular os seus próprios juízos de valor, de modo a poder decidir por si mesmo, frente às diferentes circunstâncias da vida. $\mathrm{E} o$ aprender a conviver envolve valores, respeito dos outros, de sua história, tradições e espiritualidade. Cria-se um novo espírito que, graças precisamente a essa percepção da crescente interdependência, graças a uma análise compartilhada dos riscos e 
desafios do futuro, conduza à realização de projetos comuns ou, então, a uma gestão inteligente e apaziguadora dos inevitáveis conflitos. (Delors, 2001, p.100).

Nesse aspecto, compreender a pedagogia de projeto pode ser uma metodologia que promove a inovação pedagógica é importante, pois, revendo a história dessa pratica Moura (2010) nos confirma que a origem da palavra projeto deriva do latim projectus, que significa algo lançado para frente é sair de onde se encontra em busca de novas soluções. O trabalho com projetos constitui uma das posturas metodológicas de ensino mais dinâmica e eficiente, sobretudo pela sua força motivadora e aprendizagens em situação real, de atividade globalizada e trabalho em cooperação. $O$ ato de projetar requer abertura para o desconhecido, para o não-determinado e flexibilidade para reformular as metas à medida que as ações projetadas evidenciam novos problemas e dúvidas. A pedagogia de projetos é a construção de uma prática pedagógica centrada na formação global dos estudantes, por que os processos de aprendizagem acontecem na perspectiva de pesquisa orientada. Essa alteração supõe uma redefinição não apenas dos conteúdos escolares, mas também dos tempos, espaços e processos educativos, bem como do agrupamento de alunos, ou seja, daquilo que conhecemos por classe ou turma, e que se constituiu historicamente como a unidade organizativa do trabalho escolar (Moura, 2010, p.67).

2.1.-A pedagogia de projetos e sua relevância como instrumento de avaliação: práxis de aprendizagem significativa.

Com a necessidade de reformular a aprendizagem significativa em relação ao processo de ensino-aprendizagem promovidas pela escola os educadores vêm diversificando as práticas pedagógicas diferenciadas. A abordagem pedagógica por projetos evidencia a necessidade de se trabalhar com 0 desenvolvimento de competências e habilidades, as quais se concretizam por meio de ações e de vários níveis de reflexão que congregam conceitos e estratégias, incluindo dinâmicas de trabalho que privilegiam a resolução de problemas emergentes no contexto ou 0 desenvolvimento de projetos. "As competências são construídas somente no confronto com verdadeiros obstáculos, em um processo de projeto ou resolução de problemas" (Perrenoud, 1999, p.69). Sob esse enfoque, o papel da tecnologia pode ser um aliado extremamente importante, justamente porque demanda novas formas de interpretar e representar o conhecimento, como o uso das tecnologias modernas, embora estas sejam um elemento cultural bastante expressivo, precisam ser devidamente compreendidas em termos das implicações do seu uso no processo de ensino aprendizagem.

Essa compreensão, do uso das tecnologias digitais, permite ao professor integrá-las à sua prática pedagógica com planejamento, para assim, torná-la mais eficiente e eficaz. No entanto, muitas vezes essa integração é vista de forma equivocada, e a tecnologia acaba sendo incorporada a uma atividade e direcionada apenas para instrumentalizar sua utilização, ou ainda, de forma monopolizada determinada área curricular. Neste momento, o papel do professor é imprescindível, ao demonstrar como a Pedagogia de Projetos pode promover a integração das disciplinas do currículo, bem como sua 
natural interação com as tecnologias, pois este, com um olhar mais experiente e interdisciplinar, visualiza e desenvolve o conhecimento nas suas múltiplas dimensões, facetas e disciplinas. Dessa forma, construir, investigar e resolver uma determinada situação problema, possibilita, transformar o espaço escolar em espaço vivo, colaborando para mudanças mais significativas na práxis pedagógica, como também no desenvolvimento e amadurecimento de estudantes como seres autônomos, conscientes, reflexivos, participativos e mais felizes ao produzirem conhecimento de forma consciente.

Afirmam Hernandez e Ventura (1994), que é necessário selecionar e estabelecer critérios de avaliação, decidir o que aprender, como e para quê, prestar atenção ao internacionalismo, e o que traz consigo de valores de respeito, solidariedade e tolerância, o desenvolvimento das capacidades cognitivas de ordem superior: pessoais e sociais, saber interpretar as opções ideológica e de configuração do mundo. (Hernandez e Ventura, 1994, p.46).

Para esta definição, podemos constatar que a pedagogia de projetos entendemos como uma metodologia interativa, que precisa ser aplicada à sala de aula, à escola, à vida e à sociedade, tendo em vista a construção de uma cidadania democrática, participativa e responsável. Nesta metodologia o professor administra e orienta de forma mediadora e aprende, e o estudante, por sua vez, busca informações, levanta e experimenta hipóteses, aprende e se apropria o objeto e seu referencial teórico sendo assim conduzido ao desenvolvimento da pesquisa e por consequência à produção de conhecimento. Dessa forma, os professores devem ser pioneiros em assumir uma atitude interdisciplinar ao buscar, transformar, resinificar e compartilhar 0 conhecimento, valorizando assim o processo de pesquisa que propõe uma aprendizagem significativa se contrapondo às metodologias tradicionais utilizadas, pois permite a expressão criativa possibilitando ao estudante sair do senso comum adotando um posicionamento consciente e crítico, rompendo, deste modo com 0 modelo tradicional de ensino o que pouco permite a discussão de temas e vivências significativos (Hernandez e Ventura, 1994, p.46).

Nessa perspectiva, o uso da pedagogia de projetos requer um planejamento de todo processo pedagógico e assim deixar claro o papel do estudante como responsável por sua própria aprendizagem. Para tanto, é fundamental pesquisar seriamente, desconstruir e reconstruir o conhecimento dentro desta metodologia pedagógica, pois a mesma, permite ao estudante vivenciar a realidade, percebendo-a em suas múltiplas relações, empregando neste processo suas próprias ideias e interagindo com as de outros com autonomia, respeito e seriedade. Portanto ao interpretar a realidade e significá-la, o estudante, torna-se, assim, cada vez mais autônomo em seu processo de formação e o conhecimento passa a ser fundamental e necessário nas relações sociais, favorecendo uma melhor percepção, da realidade e dos contextos, social, educacional, político e econômico (Hernandez e Ventura, 1994, p.55).

Dessa forma, é relevante destacar que o Manual Pedagógico do Parâmetro Curricular Nacional - PCN (MEC, 1997) norteia que a avaliação deve ser contínua e cumulativa, 
ou seja, durante o processo de ensino aprendizagem, precisa-se avaliar fomentando os aspectos qualitativos, e quando os resultados da aprendizagem não forem alçados deve-se oportuniza uma recuperação paralela para que o estudante sane suas dificuldades no processo e não só no final do período letivo (MEC, 1997, p.06).

E neste sentido o uso da pedagogia de projetos como instrumento de avaliação formativa é possível, pois, esta oportuniza a construção da aprendizagem a partir da informação, da pesquisa e do trabalho em grupo. Perrenoud (1999), atesta que é necessário considerar como formativa toda prática de avaliação contínua que pretenda contribuir para melhorar as aprendizagens em curso, avaliar a partir da pedagogia de projetos oportuniza a autonomia na construção do conhecimento e dá conta das práticas modernas da avaliação, que sendo contínua e efetiva regulando a práxis pedagógica durante o processo de aprendizagem. (Perrenoud, 1999, p.47).

Nesse aspecto, podemos considerar que a pedagogia de projetos é um recurso possivel, visto que oportuniza uma avaliação formativa, a qual, ajuda o estudante a aprender e a se desenvolver. Compreende-se também que esta possibilita e orienta as aprendizagens e o desenvolvimento no sentido de um projeto educativo formativo, autônomo e significativo e que ajuda o estudante a aprender, por mediações e se necessário intervenções e regulações que propiciam avanços no processo de aprendizagem. Por tanto, considerando a necessidade de estar em constante transformação tornando-se imprescindível a construção de novas habilidades para 0 processo educativo. É necessário que todos nos permanecemos reaprendendo a compreender, a comunicar-nos, a ensinar; reaprendendo a integrar o humano e 0 tecnológico; a integrar o particular, o grupal e o social, de forma significativa com uma aprendizagem inovadora.

\section{3.-Metodologia.}

A metodologia utilizada para a realização desta investigação é do tipo qualitativa, com caráter descritivo, explicativo do tipo não experimental. Ou seja, definimos por meio do método hipotético-dedutivo com apoio em referencial bibliográfico que teve como instrumento para coleta de dados a revisão de literatura que objetivou pesquisar a pedagogia de projetos e práxis pedagógicas como instrumento de avaliação inovadora no processo de ensino aprendizagem. A referida temática, necessitou de um estudo amplo em busca desse conhecimento que teve como fonte bibliográfica livros e artigos científicos.

É importante entender que a metodologia da pesquisa cientifica, o pesquisador utiliza o conhecimento anterior acumulado e analisando cuidadosamente os diferentes métodos e técnicas para obter resultados pertinentes às suas indagações. Segundo Ander-Egg (apud Marconi e Lakatos, 2003, p. 155) a pesquisa de cunho bibliográfico é um "procedimento reflexivo sistemático, controlado e crítico, que permite descobrir novos fatos ou dados, relações ou leis, em qualquer campo do conhecimento". Desse modo, esse procedimento fornece ao investigador um caminho para o conhecimento da realidade ou de verdades parciais. Valeu-se ainda do método hipotético-dedutivo que de acordo com Marconi e Lakatos (2003, p. 32), o mesmo "inicia-se com um 
problema ou uma lacuna no conhecimento científico, passando pela formulação de hipótese(s) e por um processo de inferência dedutiva, o qual testa a predição da ocorrência de fenômenos abrangidos pela referida(s) hipótese(s)". Isso é, busca compreender o problema e confirmar ou negar as hipóteses(s).

Marconi e Lakatos (2003) relata que quanto a pesquisa bibliográfica esta procura explicar um problema a partir de referências teóricas publicadas em documentos, buscando conhecer e analisar as contribuições culturais ou científicas do passado existentes sobre um determinado assunto, tema ou problema. Logo, é uma etapa importante na produção de todo trabalho científico, pois referência a pesquisa ao longo de seu desenvolvimento. Teve como instrumento para a coleta de dados a revisão de literatura que sucedeu a partir do levantamento, seleção, fichamento, análise, e organização de informações relacionadas ao tema, para a construção do trabalho. Assim, os autores versam que "através da revisão de literatura, reporta e avalia 0 conhecimento produzido em pesquisas prévias, destacando conceitos, procedimentos, resultados, discussões e conclusões relevantes para o trabalho." Entretanto, trata-se, de uma revisão pertinente a fim de fundamentar as pesquisas cientificas e proporciona ao pesquisador conhecimento sobre o tema (Marconi e Lakatos, 2003, p.79)

\section{4.-Análise dos dados.}

De acordo com o presente estudo, entendemos que é de grande importância a pedagogia de projeto como metodologia que visa à promoção e integração das disciplinas do currículo e também como instrumento de uma avaliação formativa. Após aplicação da pedagogia de projetos e a promoção da integração das diversas áreas do conhecimento em prol da formação integral dos estudantes, percebemos que os pilares: conhecer, fazer, ser e conviver que de acordo com Delors (2001), foram evidenciados na promoção, desenvolvimento e aprimoramento de competências e habilidades do público investigado que pode promover a construção significativa e integrada do conhecimento, pois, como já salientamos a educação contemporânea exige uma urgente e pulsante ressignificação dos espaços e tempos de aprendizagem: organização, rotinas, ideologias, currículo, relações e papéis, tendo como principal objetivo o desenvolvimento pleno e integral da criança, do jovem e do cidadão em todos os seus aspectos: físico, psíquico, emocional e social em suas múltiplas e facetadas dimensões.

Nesta dialética, entende-se que a construção do conhecimento se efetiva em íntima relação com o contexto e este se apropria do mesmo, sendo assim, é impossível distinguir, a princípio, os aspectos cognitivos, emocionais e sociais nesta interação global, interativa e complexa, onde conhecer, reconhecer e interferir na vida real não se encontra dissociado do processo ensino aprendizagem, tão pouco na separação ou compartimentalização do conhecimento. Hernandez e Ventura (1994) colabora enfatizando que o projeto rompe com as fronteiras disciplinares, tornando-as permeáveis na ação de articular diferentes áreas de conhecimento, mobilizadas na investigação de problemáticas e situações da realidade. A partir da pedagogia de projetos há possibilidades de integrar as disciplinas, as quais, estabelecem 
articulações horizontais numa relação de reciprocidade entre elas, com o desígnio de promover a unicidade do conhecimento.

Desse modo, o estudo com revisão bibliográfica motivou a busca de uma investigação de bibliográfica, que tem como pesquisados professores e alunos do $1^{\circ}$ ano do Ensino Médio, em Colégio Público na cidade de Salvador, Bahia- Brasil.

A motivação em ir a campo, surgiu por que se observa frequentemente, verbalizam não perceberem a aplicabilidade do que se trabalha na escola em sua vida cotidiana e por conseguinte em sua vida profissional. Esta busca de informações se constitui a partir da falta de motivação, interesse percebido nos estudantes deste ciclo, de estudantes do Ensino Médio.

Em base a nossas pesquisas verificamos que é fundamental planejar as ações pedagógicas evidenciando 0 desenvolvimento da capacidade de eleger, continuamente, metas a partir de um quadro de valores historicamente situado e de lançar-se em busca das mesmas. Nesse sentido, a pedagogia de projetos como processo de aprendizagem que busca uma referência de futuro e uma abertura para a inovação está demostrado de acordo com o que referenciamos no quadro abaixo:

Quadro. -01- pedagogia de projetos

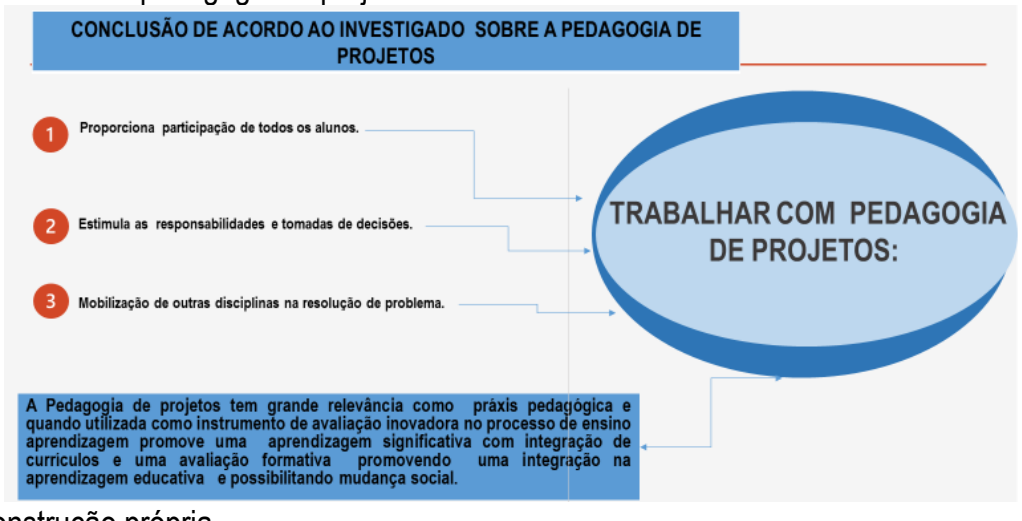

Construção própria.

Assim, após esta pesquisa bibliográfica buscamos elencar as possíveis mudanças na práxis pedagógica do professor e na aprendizagem do estudante, bem como em sua atitude e ideias acerca do real valor da educação de qualidade e a produção de conhecimento significativo.

\section{5.-Conclusão.}

Nesta pesquisa bibliográfica buscamos propor uma abordagem baseada em projetos, onde a escola incentiva de forma interdisciplinar o conhecimento, 0 aprendizado por meio da experiência e o desenvolvimento da autonomia dos alunos.

E relação a nossa hipótese que a pedagogia de projetos promove a integração das disciplinas do currículo, além de oportunizar a aprendizagem que perpasse pelos pilares da educação supracitados, está confirmada com base em que, o uso de metodologias interativas, recursos tecnológicos aliados a outras ferramentas 
pedagógicas podem acompanhar as mudanças da sociedade e atender às exigências do estudante contemporâneo que ostenta uma aprendizagem mais autônoma e significativa. A pedagogia de projetos quando bem planejada e aplicada, revoluciona as atuais estruturas engessadas das instituições de ensino. Significa, não apenas 0 professor ser interdisciplinar, mas sim a instituição assumir esse novo paradigma, permitir-se ao novo, possibilitando o mesmo a todos os sujeitos que dela fazem parte estudantes, pais, professores, gestores, funcionários e comunidade escolar, percebam-se como promotores do conhecimento, pois enquanto não houver uma atitude dialógica entre os diversos setores das instituições educacionais não existirá o contexto interdisciplinar. Ser interdisciplinar, atuar de maneira interdisciplinar é perceber o conhecimento de forma integrada, como se viu no decorrer deste estudo, consiste, antes de tudo, no diálogo entre sujeitos, conceitos, teorias, métodos e diferentes disciplinas.

Torna de imprescindivel destacar, que os objetivos primordiais da metodologia da pedagogia de projetos é contextualizar uma aprendizagem significativa, mas, para isso é fundamental que o professor avance e se permita a quebrar paradigmas e refletir sobre as amarras da Educação formal, passiva e pouco significativa. Dessa forma, é urgente que no ambiente educacional, o olhar inovador seja efetivado, em prol de evidenciar mudanças significativas e eficazes nas formas de ensinar, aprender, construir, reconstruir, priorizando a formação dos estudantes, e cidadãos críticos, reflexivos, participativos e conscientes, que estabeleçam relações de respeito e justiça social.

Assim, eferente ao nosso problema de investigação, em saber como a Pedagogia de Projeto pode promover a integração das disciplinas do currículo em uma práxis pedagógica interativa e um instrumento de avaliação formativo que promova 0 conhecer, fazer, ser e conviver em prol aprendizagem significativa. Este foi confirmada, após investigação bibliográfica que nos demonstrou que é necessário quebrar os paradigmas da educação tradicional, buscando o desenvolvimento da aprendizagem de forma integrada, dialógica e Inter e Transdisciplinar, onde o estudante seja 0 principal protagonista.

Dessa forma, a metodologia utilizada na realização dessa investigação está pautada em pesquisas sérias que oportunizaram a compreensão de nossa problemática, e nos aportou uma visão fidedigna da temática estudada. Vale enfatizar que, após estudo, acreditamos que é essencial a investigação de campo para assim, demonstrar de forma empírica e aplicabilidade da pedagogia de projetos no processo de ensino aprendizagem para oportunizar uma aprendizagem mais interativa, interdisciplinar, significativa e independente.

\section{6.-Referências.}

Dawbor, L. (1994) O espaço do conhecimento. In autores (s/d): A revolução tecnológica e os novos paradigmas da sociedade. Belo Horizonte: IPSO.

Delors, J. (2001). Educação: um tesouro a descobrir. São Paulo: Cortez. 
Dewey, J. (1967). Vida e Educação. São Paulo: Melhoramentos.

Hernandez, F., Ventura, M. (1994). Os projetos de trabalho: uma forma de organizar os conhecimentos escolares. O conhecimento é um caleidoscópio. Porto Alegre: Artes Medicas.

Luckesi, C.C. (2006). Avaliação da aprendizagem escolar: estudos e proporções. 9ed. São Paulo: Cortez.

Marconi, M. A., Lakatos, E.V. (2003). Metodologia Cientifica. São Paulo: Atlas.

MEC (1997). Parâmetro Curricular Nacional. Brasília: Editorial Ministério da Educação.

Morin, E. (2001). A realização dos saberes. O desafio do século XXI. Rio de Janeiro: Editora Bertrand Brasil.

Moura, D.P. (2010). Pedagogia de Projetos: Contribuições para Uma Educação Transformadora. Acesso 22/03/2019 às 12:16. Disponível na Internet em http://www.pedagogia.com.br/artigos/pedegogiadeprojetos/index.php

Perrenoud, P. (1999). Construindo competências desde a escola. TRAD. Bruno Charles Magne. Porto Alegre: Artes Médicas Sul. 